\title{
Green-Synthesization of Silver Nanoparticles Using Endophytic Bacteria Isolated from Garlic and Its Antifungal Activity against Wheat Fusarium Head Blight Pathogen Fusarium graminearum
}

\author{
Ezzeldin Ibrahim ${ }^{1,2}{ }^{,}$Muchen Zhang ${ }^{1}$, Yang Zhang ${ }^{1}$, Afsana Hossain ${ }^{1,3}$, Wen Qiu ${ }^{1}$, Yun Chen ${ }^{1}$, \\ Yanli Wang ${ }^{4, *}$, Wenge $\mathrm{Wu}^{5, *}$, Guochang Sun ${ }^{4}$ and ${\mathrm{Bin} \mathrm{Li}^{1, *}}^{1,}$ \\ 1 State Key Laboratory of Rice Biology and Ministry of Agriculture Key Lab of Molecular Biology of Crop \\ Pathogens and Insects, Institute of Biotechnology, Zhejiang University, Hangzhou 310058, China; \\ ezzelbehery8818@yahoo.com (E.I.); 11816060@zju.edu.cn (M.Z.); 0618151@zju.edu.cn (Y.Z.); \\ afsana_07@yahoo.com (A.H.); wenwen20101010@163.com (W.Q.); chenyun0927@zju.edu.cn (Y.C.) \\ 2 Department of Vegetable Diseases Research, Plant Pathology Research Institute, Agriculture Research \\ Centre, Giza 12916, Egypt \\ 3 Department of Plant Pathology and Seed Science, Sylhet Agricultural University, Sylhet 3100, Bangladesh \\ 4 State Key Laboratory for Quality and Safety of Agro-products, Institute of Plant Protection and Microbiology, \\ Zhejiang Academy of Agricultural Sciences, Hangzhou 310021, China; sungc01@sina.com \\ 5 Rice Research Institute, Anhui Academy of Agricultural Sciences, Hefei 230001, China \\ * Correspondence: ylwang88@aliyun.com (Y.W.); aaasrri@163.com (W.W.); libin0571@zju.edu.cn (B.L.)
}

Received: 31 December 2019; Accepted: 24 January 2020; Published: 27 January 2020

Abstract: Nanoparticles are expected to play a vital role in the management of future plant diseases, and they are expected to provide an environmentally friendly alternative to traditional synthetic fungicides. In the present study, silver nanoparticles (AgNPs) were green synthesized through the mediation by using the endophytic bacterium Pseudomonas poae strain $\mathrm{CO}$, which was isolated from garlic plants (Allium sativum). Following a confirmation analysis that used UV-Vis, we examined the in vitro antifungal activity of the biosynthesized AgNPs with the size of $19.8-44.9 \mathrm{~nm}$, which showed strong inhibition in the mycelium growth, spore germination, the length of the germ tubes, and the mycotoxin production of the wheat Fusarium head blight pathogen Fusarium graminearum. Furthermore, the microscopic examination showed that the morphological of mycelia had deformities and collapsed when treated with AgNPs, causing DNA and proteins to leak outside cells. The biosynthesized AgNPs with strong antifungal activity were further characterized based on analyses of X-ray diffraction, transmission electron microscopy, scanning electron microscopy, EDS profiles, and Fourier transform infrared spectroscopy. Overall, the results from this study clearly indicate that the biosynthesized AgNPs may have a great potential in protecting wheat from fungal infection.

Keywords: F. graminearum; nanoparticles; SEM; FTIR; antifungal activity; mycotoxins

\section{Introduction}

Fusarium head blight caused by Fusarium graminearum is a great obstacle to wheat production in the world [1]. This fungal pathogen is also able to infect other cereal crops such as rice, barley, and maize [1-3]. In China, this pathogen has not only resulted in a heavy loss of more than 3.41 million tons in wheat during 2000-2018 [4,5], it has also been able to produce some mycotoxins in infected wheat grains that pose a serious threat to the safety and health of humans and animals [6-8]. Nowadays, chemical fungicides are used as the main strategy to protect wheat from this fungal infection. However, 
their long-time use has resulted in the increased fungicide resistance of the fungal strains [9]. In addition, concerns have been raised regarding the safety of fungicides to human health, the environment and the ecosystem [10]. Therefore, it is very necessary to develop a new alternate method to inhibit or kill this pathogen.

Various metals nanoparticles have been widely applied in agriculture due to their distinctive features such as antimicrobial activity, catalytic activity, magnetic and electrical properties [11,12]. Furthermore, several studies have demonstrated that metal nanoparticles have been well documented as fungicides $[10,13]$. For example, silver nanoparticles (AgNPs) have been shown to significantly inhibit the hyphal growth of a variety of foliar and soil-borne plant pathogen [14,15]. In addition, more and more attention has been paid to the biosynthesis of AgNPs by using eco-friendly materials, such as plant extracts and microorganisms, which are safer than traditional physical and chemical methods [16-19].

In this study, we biosynthesized AgNPs by using the endophytic bacterium Pseudomonas poae strain $\mathrm{CO}$, and then we characterized the AgNPs with strong antifungal activity against $F$. graminearum. In addition, we also evaluated the antifungal mechanism of the biosynthesized AgNPs against F. graminearum.

\section{Materials and Methods}

\subsection{Microorganisms Used in This Study}

F. graminearum strain PH-1 [20] was kindly provided by Professor Yanni Yin in the Institute of Biotechnology, Zhejiang University, Hangzhou, China. The endophytic bacterium P. poae strain CO was isolated from fresh leaves of a garlic plant grown in Hangzhou, Zhejiang Province, China. This strain was identified through $16 \mathrm{~S}$ rRNA gene sequence analysis.

\subsection{Biosynthesis of AgNPs}

In this study, the endophytic bacterium $P$. poae strain $\mathrm{CO}$ was used to mediate the biosynthesis of AgNPs, and this process was performed according to the method of Fouad et al. [21] with slight modification. In brief, the endophytic bacterium P. poae strain $\mathrm{CO}$ was inoculated in a nutrient broth (10 $\mathrm{g}$ of tryptone, $3 \mathrm{~g}$ of beef extract, $2.5 \mathrm{~g}$ of glucose, and $5 \mathrm{~g}$ of $\mathrm{NaCl}$ per liter; $\mathrm{pH}$ 7.0; all ingredients were purchased from Sangon Biotech, Shanghai, and then incubated at $30^{\circ} \mathrm{C}$ at $200 \mathrm{rpm}$ for 2 days. Ten milliliters of culture filtrates (CF) were mixed with $90 \mathrm{~mL}$ of $3 \mathrm{mM}$ aqueous of silver nitrate (Cat. no. 10018461; Sinopharm, Shanghai, China) in a $250 \mathrm{~mL}$ Erlenmeyer flask, followed by shaking at $200 \mathrm{rpm}, 30^{\circ} \mathrm{C}$ for 4 days in darkness. A nutrient broth of the same volume was used as the control. The biosynthesis of AgNPs was noted by the change of the color from light yellow to dark brown, while the formation of AgNPs was assured by UV-visible spectrometry from 200 to $800 \mathrm{~nm}$ at a $1 \mathrm{~nm}$ resolution by using a Shimadzu UV-2550 spectrometer (Shimadzu, Kyoto, Japan). The pellets were collected by centrifuging at 10,000 $\mathrm{g}$ for $20 \mathrm{~min}$ and washing twice with double distilled water $\left(\mathrm{ddH}_{2} \mathrm{O}\right)$. The biosynthesized AgNPs were freeze-dried for future use.

\subsection{Antifungal Activity of the Biosynthesized AgNPs}

\subsubsection{Inhibition of AgNPs on Mycelium Growth}

The inhibitory effect of AgNPs of 5, 10,15 and $20 \mu \mathrm{g} / \mathrm{mL}$ on the mycelium growth of $F$. graminearum strain $\mathrm{PH}-1$ was determined according to the method of Spence et al. [22] in both a potato dextrose agar (PDA) medium, which consisted of $200 \mathrm{~g}$ of potato infusion, $20 \mathrm{~g}$ of dextrose and $20 \mathrm{~g}$ of agar per liter ( $\mathrm{pH} 7.0$ ), and potato dextrose broth (PDB), which consisted of $200 \mathrm{~g}$ of potato infusion and $20 \mathrm{~g}$ of dextrose per liter ( $\mathrm{pH}$ 7.0). The mycelium growth in the PDA medium was measured by inoculating a disk ( $5 \mathrm{~mm}$ in diameter) of 5-day-old fungus in the middle of a dish that contained the mixture of the PDA medium with different concentrations of AgNPs and then incubating at $27^{\circ} \mathrm{C}$ for 5 days. 
The PDA medium without AgNPs was used as the control. The fungal growth in the PDA broth was determined by inoculating a disk ( $5 \mathrm{~mm}$ in diameter) of 5-day-old fungus in a PDA broth containing AgNPs of different concentrations and then measuring the dry weight of the mycelium after 5 days of incubation at $27^{\circ} \mathrm{C}$. The PDB medium without AgNPs was used as the control.

\subsubsection{Effect of AgNPs on Spore Germination and Length of Germ Tubes}

The effect of AgNPs at 5, 10,15 and $20 \mu \mathrm{g} / \mathrm{mL}$ on the spore germination and length of the germ tubes of F. graminearum strain PH-1 were determined according to the method of Chen et al. [23] with slight modifications. In brief, a $100 \mu \mathrm{L}$ of spore suspension $\left(1 \times 10^{6}\right.$ spores per $\left.\mathrm{mL}\right)$ that were prepared as described by Wu et al. [24] were mixed with $100 \mu \mathrm{L}$ of AgNPs in the tubes with final concentrations of $5,10,15$ and $20 \mu \mathrm{g} / \mathrm{mL}$. The tubes containing the same volume of spore suspensions and $\mathrm{ddH}_{2} \mathrm{O}$ was used as the control. Then, $50 \mu \mathrm{L}$ of the mixture was transferred onto concave slides and incubated at $28^{\circ} \mathrm{C}$ for $7 \mathrm{~h}$ in the dark. The spore germination rate and the length of germ tubes were recorded by using the light microscope. Each treatment had three replicates, and the experiment was repeated twice.

\subsubsection{Effect of AgNPs on Deoxynivalenol Production}

The inhibition of the deoxynivalenol (DON) production of $F$. graminearum strain $\mathrm{PH}-1$ was tested according to the method of $\mathrm{Li}$ et al. [25] with slight modifications. In brief, a $1 \mathrm{~mL}$ of spore suspension $\left(1 \times 10^{6}\right.$ spores $\left./ \mathrm{mL}\right)$ of $F$. graminearum strain PH-1 was inoculated with $100 \mathrm{~mL}$ of GYEP that contained the indicated concentrations of AgNPs. The Erlenmeyer flask was incubated at $28^{\circ} \mathrm{C}$ and $175 \mathrm{rpm}$ for one week. The supernatant was used to determine DON production by using DON Plate Kit ELISA (Shanghai Yijishiye, Zhenjiang, China), and the inhibition of DON was calculated.

\subsection{Antifungal Mechanism of the Biosynthesized AgNPs}

\subsubsection{Effect of AgNPs on the Hyphal Morphology}

The effect of AgNPs on the hyphal morphology of F. graminearum strain PH-1 was determined based on the method used by Gao et al. [26] with slight modifications. In brief, a mycelial disk (10 $\mathrm{mm}$ in diameter) was picked up from the PDA medium with and without AgNPs $(10 \mu \mathrm{g} / \mathrm{mL})$ and then observed by using both scanning electron microscopy (SEM; TM-1000, Hitachi, Japan) and transmission electron microscopy (TEM; JEM-1230, JEOL, Akishima, Japan).

\subsubsection{Effect of AgNPs on the Leakage of DNA and Proteins}

The effect of AgNPs on the leakage of DNA and proteins from F. graminearum strain PH-1 cells was determined by measuring the optical density (OD) of the spore supernatant at 260 and $280 \mathrm{~nm}$, and this process was performed according to the method of Khalil et al. [16] with slight modifications. In brief, the spore suspension $\left(1 \times 10^{6}\right.$ spores $\left./ \mathrm{mL}\right)$ was prepared by incubating . graminearum strain $\mathrm{PH}-1$ at $28^{\circ} \mathrm{C}$ for $24 \mathrm{~h}$ in the PDB medium, which was supplemented with four different concentrations of AgNPs. The PDB medium without AgNPs was used as a control.

\subsection{Characterization of the Biosynthesized AgNPs}

The functional group of the biosynthesized AgNPs with antifungal activity was determined by Fourier transform infrared spectroscopy (FTIR), which was carried out as described by Hossain et al. [20]. In brief, $1 \mathrm{mg}$ of freeze-dried AgNP powders were mixed with $\mathrm{KBr}(300 \mathrm{mg})$, and the FTIR was recorded in the spectral range of $500-4000 \mathrm{~cm}$ by using an AVATAR 370 FTIR spectrometer (Thermo Nicolet, MA, USA). Furthermore, the crystalline nature of the biosynthesized AgNPs was analyzed by X-ray diffraction (XRD), as described by Hossain et al. [20] by using an XPert PRO diffractometer (Holland) with a detector voltage of $45 \mathrm{kV}$ and a current of $40 \mathrm{~mA}$ while using $\mathrm{CuKo}$ radiation. In addition, the morphology of the biosynthesized AgNPs was recorded through 
the observation of both TEM (JEM-1230, JEOL, Tokyo, Japan) and SEM (SEM, TM-1000, Hitachi, Japan), which were performed according to the method of [18]. The silver element of the AgNPs was confirmed with an energy dispersive spectrometer (EDS).

\subsection{Statistical Analysis}

All experiments were done by using a completely randomized design, and the results are expressed as mean \pm SD (standard deviation). Statistical analysis was performed by using the SPSS software package 16.0 version (SPSS Inc., Chicago, IL, USA). The variations between the groups were estimated by using the analysis of the different test. The results were statistically significant when the value was $p<0.05$ or $<0.01$.

\section{Results and Discussion}

\subsection{Biosynthesis and Confirmation of AgNPs}

The procedure for the biosynthesis of AgNPs is shown in Figure 1. The synthesis of AgNPs was justified based on the result that the color changed from light yellow to dark brown following the incubation of $\mathrm{AgNO}_{3}$ with the $\mathrm{CF}$ of endophytic bacteria for four days, suggesting $\mathrm{Ag}^{+}$reduction to $\mathrm{Ag}^{0}$ in the $\mathrm{AgNO}_{3}$ solution. In contrast, no change was observed in the color of the control sample. This result suggests that the CF of endophytic bacteria may play a key role in the biosynthesis of AgNPs. Furthermore, the formation of AgNPs was confirmed by the results of UV spectrometers, which showed a spectrum of surface plasmon resonance (SPR) at the $422 \mathrm{~nm}$ absorption band (Figure 1). Interestingly, the result of this study is consistent with the spectra contained in the literature regarding silver nanoparticles $[20,22,27,28]$.

This study first reported that the endophytic bacterium P. poae that was isolated from garlic plants was able to mediate the biosynthesis of AgNPs. These bacteria have been used as a biological source in the biosynthesis of AgNPs, but the mechanism of bacteria for AgNPs biosynthesis is still unknown. Interestingly, a lot of previous reports have revealed the existence of various biomolecules that are produced by bacteria such as alkaloids, phenolic compounds, enzymes, co-enzymes, proteins, amino acids, polysaccharides, and vitamins, all of which have been able to act as effective agents for converting $\mathrm{Ag}^{+}$to $\mathrm{Ag}^{0}[19,20,29,30]$. Therefore, it could be inferred that these biomolecules that are produced by bacteria may play a key role in the mediation of AgNPs biosynthesis. 
A
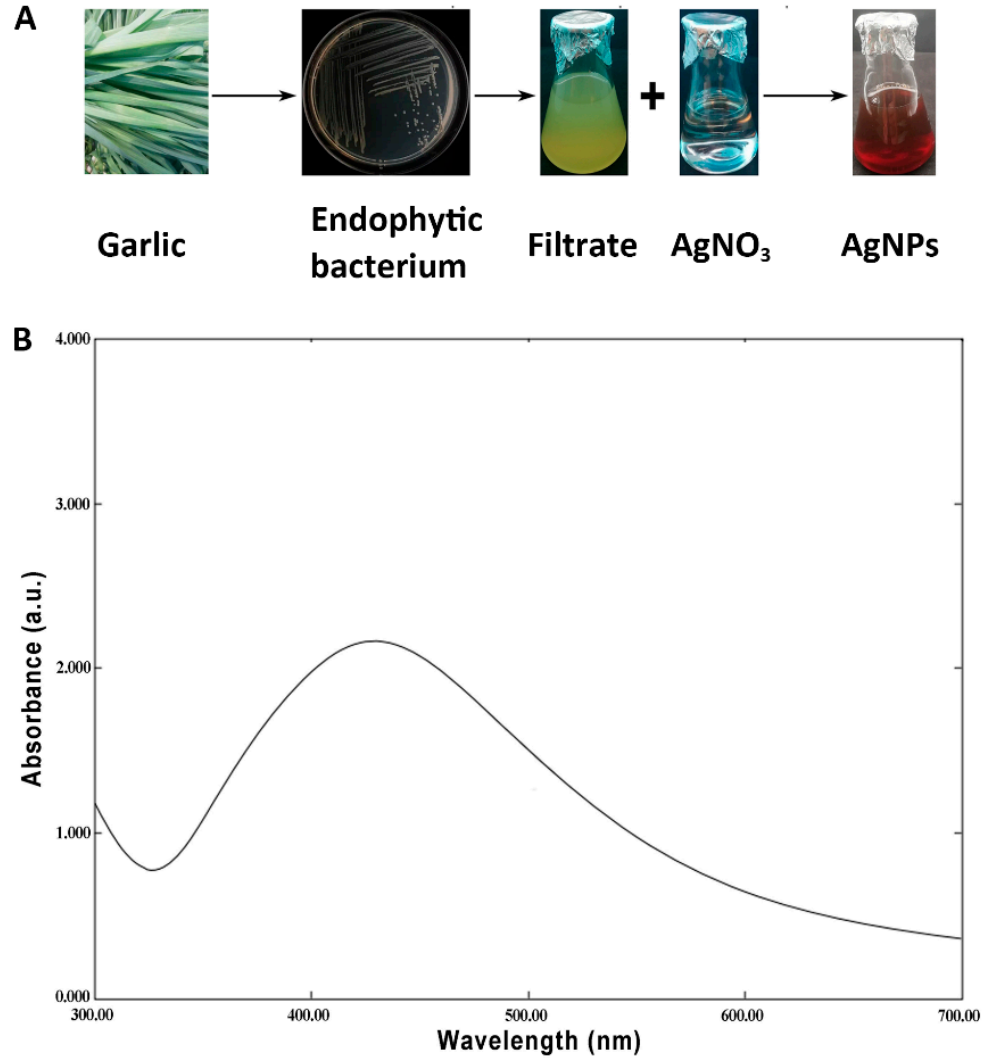

Figure 1. Confirmation of biosynthesized silver nanoparticles (AgNPs). (A) Color changes from light yellow to dark brown following the incubation of $\mathrm{AgNO}_{3}$ with the culture filtrates of the endophytic bacteria Pseudomonas poae strain CO isolated from garlic. (B) UV-Vis spectrum of AgNPs that were synthesized by the endophytic bacteria P. poae strain CO.

\subsection{Antifungal Activity and Mechanism}

\subsubsection{Inhibition of Mycelium Growth}

The results of this study showed that the mycelium growth of F. graminearum strain PH-1 in PDA and PDB mediums was strongly suppressed by AgNPs. regardless of the concentration, as shown in Figure 2. The inhibitory effect on the mycelium growth in the PDA and PDB mediums increased with the increase of the AgNP concentrations. Indeed, AgNPs at 5, 10, 15 and $20 \mu \mathrm{g} / \mathrm{mL}$ caused 45.56\%, $62.22 \%, 72.78 \%$ and $80.56 \%$, respectively, inhibitions in the mycelium growth in the PDA medium, and they caused $48.56 \%, 65.11 \%, 75.50 \%$ and $85.78 \%$, respectively, inhibitions in the mycelium growth in the PDB medium. In agreement with results of this study, previous studies have indicated that AgNPs are able to be used as antifungal agents to suppress many fungal plant diseases [15,30-35]. 

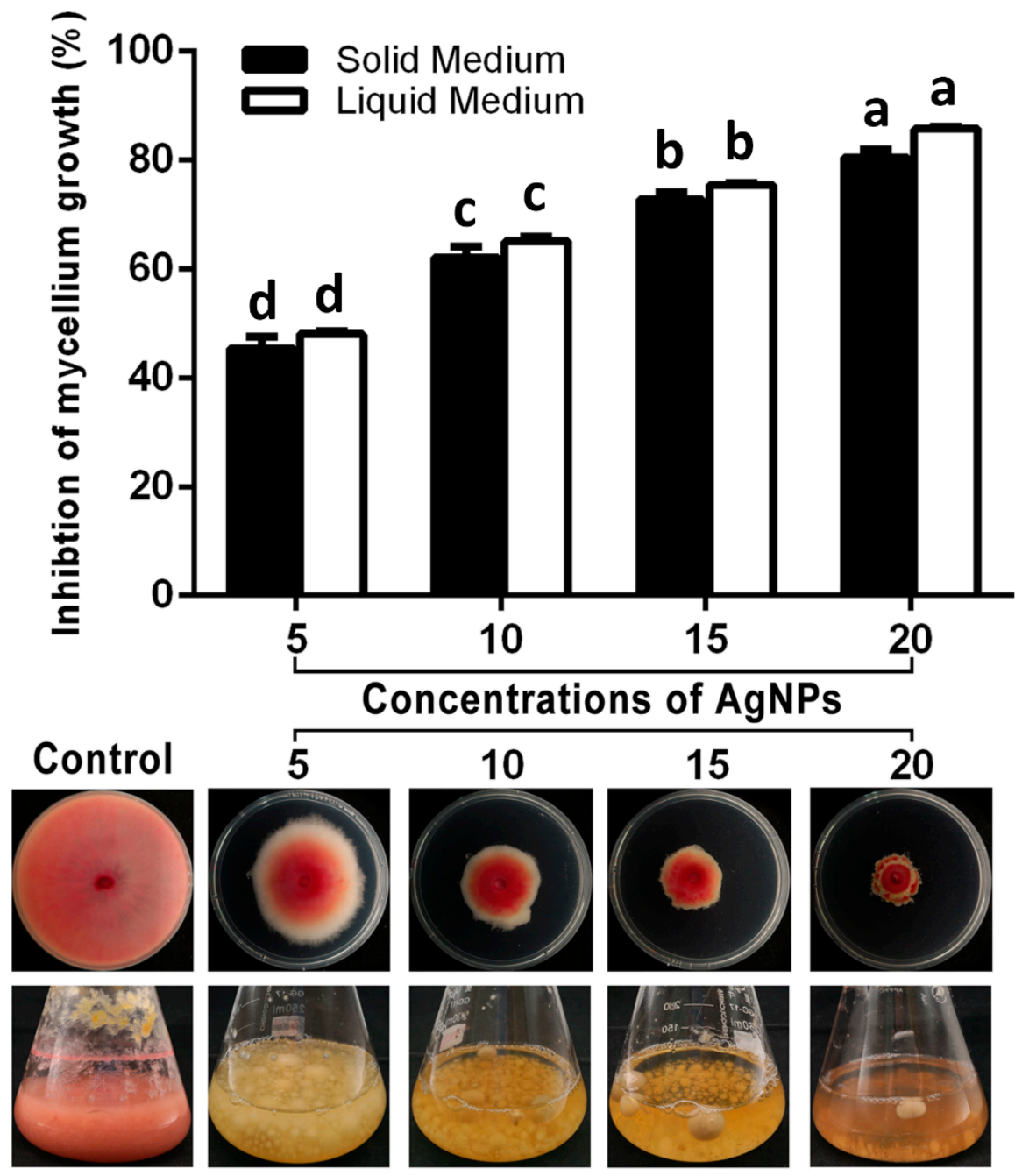

Figure 2. In vitro antifungal activity of AgNPs biosynthesis at different concentrations against Fusarium graminearum strain $\mathrm{PH}-1$ in potato dextrose agar (PDA) and potato dextrose broth (PDB) mediums. Data are a mean value \pm standard error of three replicates, and bars with the same letters are significantly different in LSD test $(p<0.05)$.

\subsubsection{Damage of Cell Walls by Morphological Observation}

The fungal cell wall is a complex structure that plays a key role in determining cell shape. Furthermore, the cell wall is able to protect fungal cells from environmental stress, including changes in osmolality, temperature and $\mathrm{pH}[11,30,36]$. The data from the use of SEM and TEM in this study indicated that cell wall remained intact with hyphae, showing a normal structural property of F. graminearum strain PH-1 in the absence of biosynthesized AgNPs. In contrast, the cell walls of F. graminearum strain $\mathrm{PH}-1$ was severely damaged and the hyphae showed an abnormal structural property in the presence of the biosynthesized AgNPs (Figure 3). Similar effects of AgNPs have been reported on the cell walls of several other pathogenic fungi such as Alternaria alternata, Botrytis cinera and Trichosporon asahii [37]. 


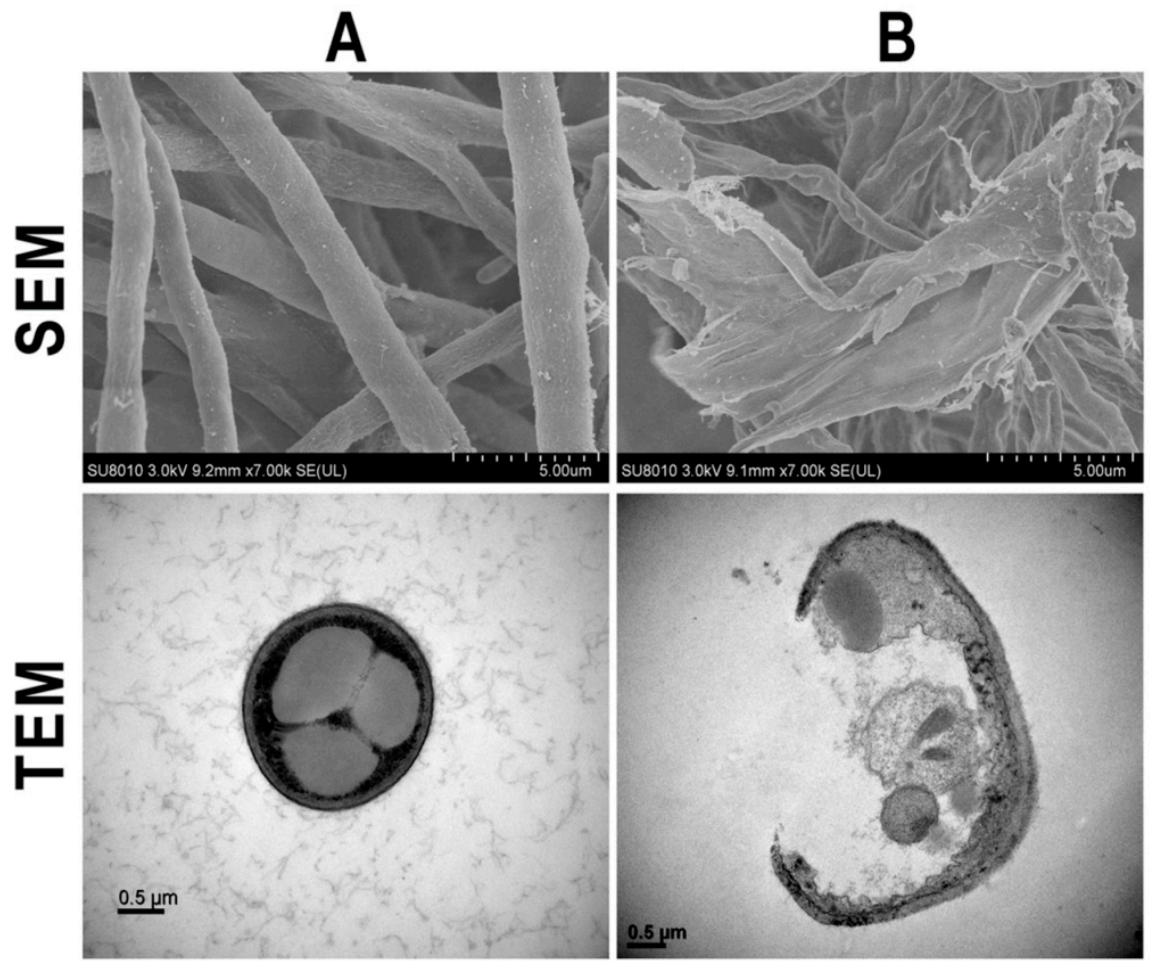

Figure 3. Microscopic images of SEM and TEM of F. graminearum strain $\mathrm{PH}-1$ in the absence (A) and presence (B) of the synthesized AgNPs.

\subsubsection{Damage of Cell Walls by Determination of Leakage DNA and Proteins}

The results from this study indicated that the biosynthesized AgNPs of different concentrations caused the leakage of DNA and proteins from F. graminearum strain PH-1 spore cells. Furthermore, the leakage of DNA and proteins increased with the increase of the concentration of the biosynthesized AgNPs (Figure 4). Indeed, the OD260 and OD280 values of strain PH-1 spore cells were 0.95 and 1.74, respectively, in the absence of the biosynthesized AgNPs. However, in the presence of the biosynthesized AgNPs at 5, 10, 15 and $20 \mu \mathrm{g} / \mathrm{mL}$, the OD260 values were 1.70, 2.10, 2.45 and 2.67, respectively (Figure 4A), while the OD280 values were 2.70, 3.23, 3.86 and 4.47, respectively (Figure 4B). In agreement with the results of this study, previous studies have indicated that the accumulation of AgNPs on the cell membrane is able to cause cell membrane damage, which results in leakage and the release of cellular contents, including DNA and proteins $[16,30,38]$. 


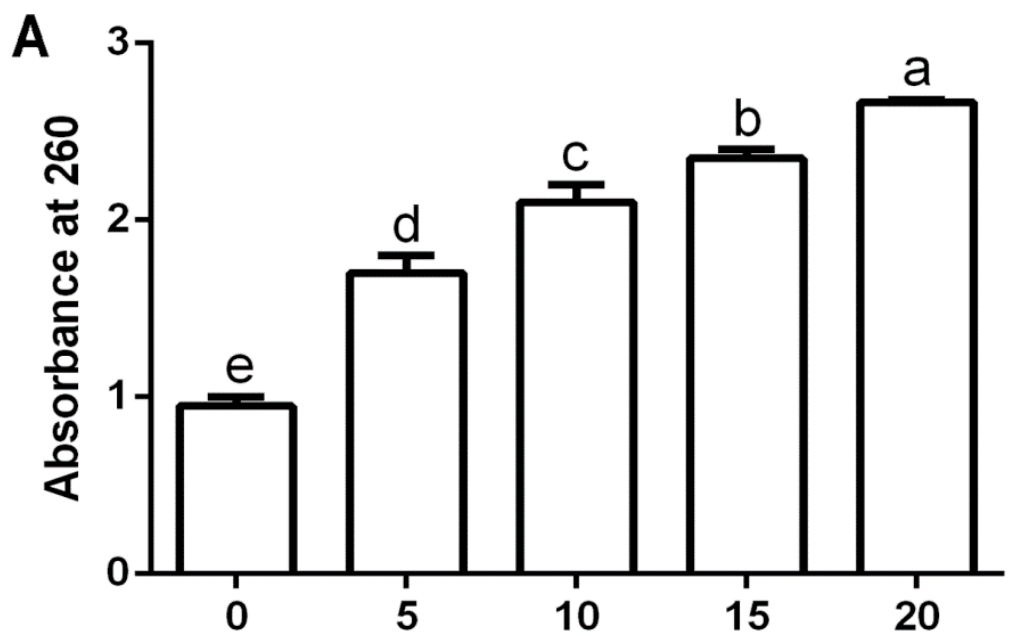

Concentrations of AgNPs $(\mu \mathrm{g} / \mathrm{ml})$

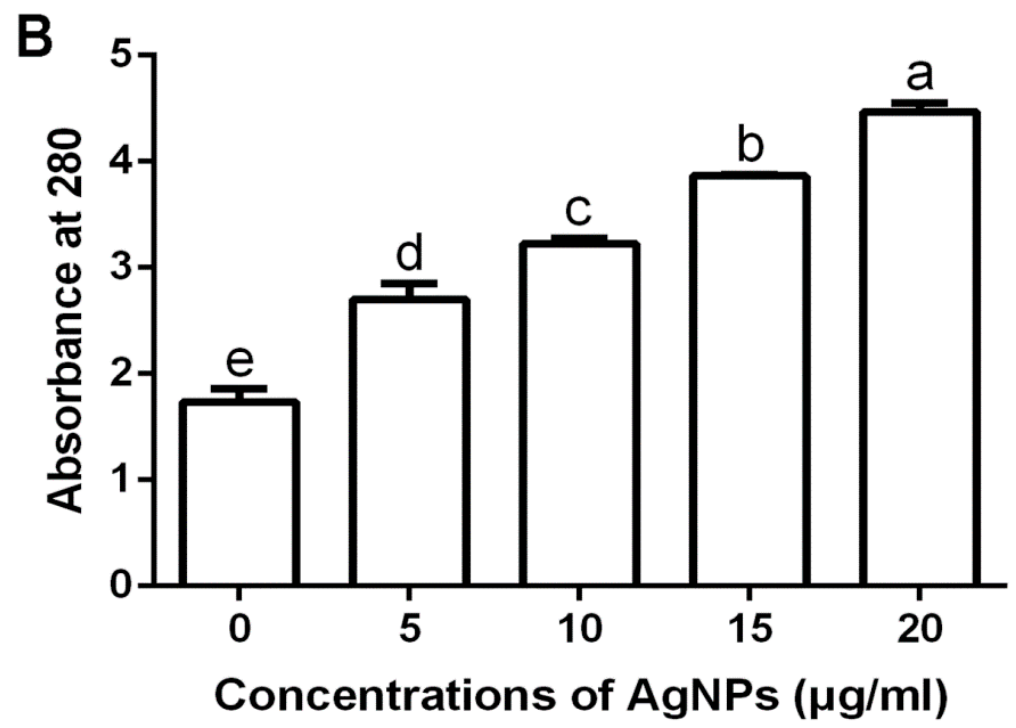

Figure 4. Biosynthesized AgNPs at different concentrations caused the leakage of DNA (A) and proteins (B) from F. graminearum strain $\mathrm{PH}-1$ spore cells. Data are a mean value \pm standard error of three replicates, and bars with the same letters are significantly different in LSD test $(p<0.05)$.

\subsubsection{Inhibition of Spore Germination and Germ Tube Growth}

The results of this study indicated that the biosynthesized AgNPs at four different concentrations were able to effectively suppress the spore germination and germ tube growth of $F$. graminearum strain $\mathrm{PH}-1$. The inhibitory effect increased with the increase of the concentration of the biosynthesized AgNPs. Indeed, the spore germination rate was $98.00 \%$, while the length of the germ tubes was $76.14 \mu \mathrm{m}$ in absence of the biosynthesized AgNPs. In the presence of AgNPs at 5, 10, 15 and $20 \mu \mathrm{g} / \mathrm{mL}$, the spore germination rates were $85.00 \%, 67.67 \%, 44.00 \%$ and $24.33 \%$, respectively (Figure 5 ), and the germ tube lengths were 57.86, 48.57, 31.86, and $21.14 \mu \mathrm{m}$ (Figure 6), respectively. It is well known that germinated spores have a key role in colonization and infection of pathogenic fungi to plants $[24,39]$. Therefore, the inhibition of spore germination will greatly reduce the infection risk of these fungal pathogens to wheat plants. AgNPs have been observed to have a significant effect on the length and pattern of germ tubes. 


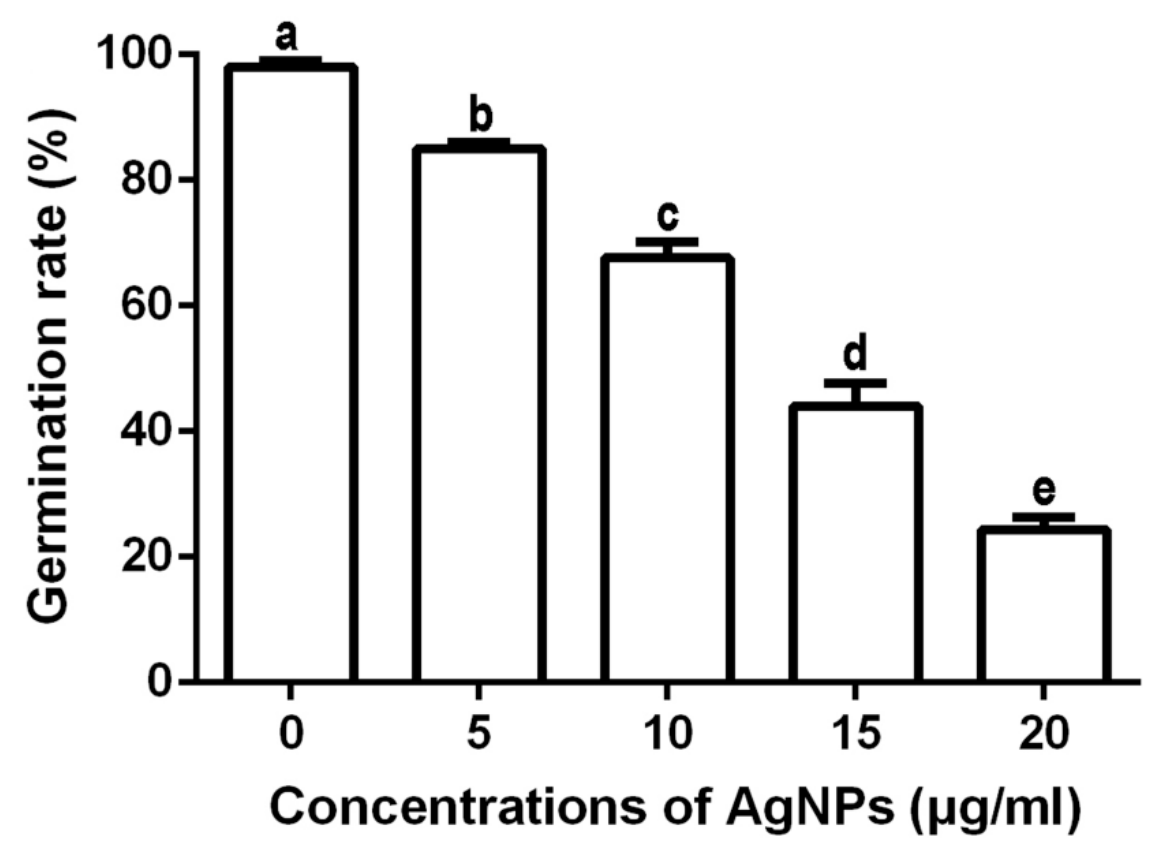

Figure 5. Effect of the synthesized AgNPs of different concentrations on spores' germination rate of F. graminearum strain $\mathrm{PH}-1$. The biosynthesized AgNPs at four different concentrations were able to effectively suppress the spore germination. Data are a mean value \pm standard error of three replicates, and bars with the same letters are significantly different in LSD test $(p<0.05)$.

\section{Concentrations of AgNPs $(\mu \mathrm{g} / \mathrm{ml})$}

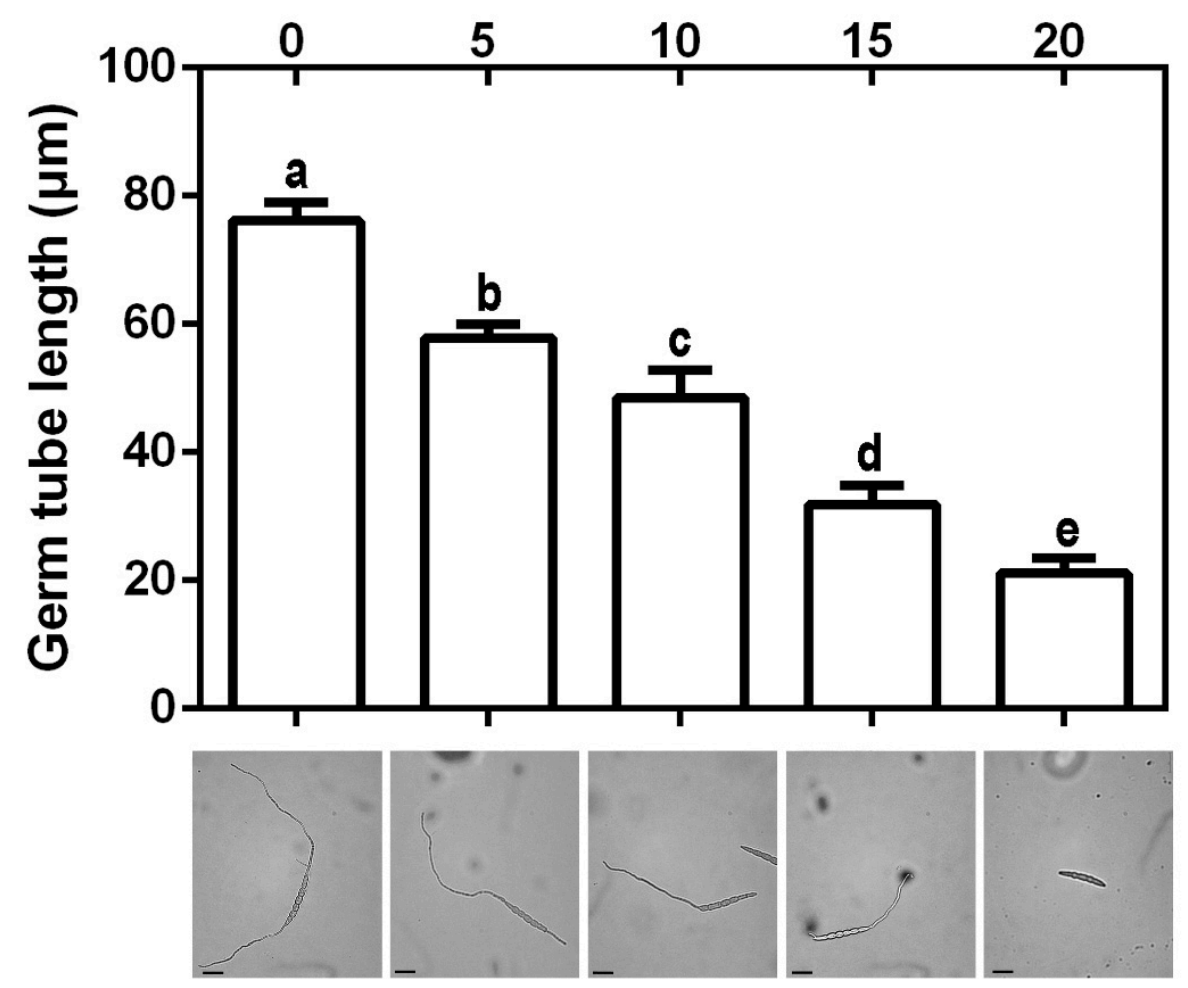

Figure 6. Effect of the synthesized AgNPs at four different concentrations on germ tube growth. The biosynthesized AgNPs were able to inhibit germ tube growth of F. graminearum strain PH-1. Data are a mean value \pm standard error of three replicates, and bars with the same letters are significantly different in LSD test $(p<0.05)$. 


\subsubsection{Effect of AgNPs on DON Production}

DON is one of the most important mycotoxins that causes damage to human and animal health [40]. The results of this study showed that the DON production of F. graminearum strain PH-1 in the GYEP medium was strongly inhibited by the biosynthesized AgNPs at different concentrations. In the absence of the biosynthesized AgNPs, the DON production rate of strain PH-1 was $15.32 \mu \mathrm{g} / \mathrm{g}$. In the presence of the biosynthesized AgNPs at 5, 10, 15, and $20 \mu \mathrm{g} / \mathrm{mL}$, the DON production rates were 9.91, 6.22, 3.50 and $2.04 \mu \mathrm{g} / \mathrm{g}$, respectively, (Figure 7). The result of this study suggest that biosynthesized AgNPs have a great potential in reducing DON contamination in cereals that are infected by F. graminearum. In agreement with the result of our study, biosynthesized AgNPs have been found to be effective in thwarting the production of the mycotoxins of Aspergillus flavus and Aspergillus ochraceus [16].

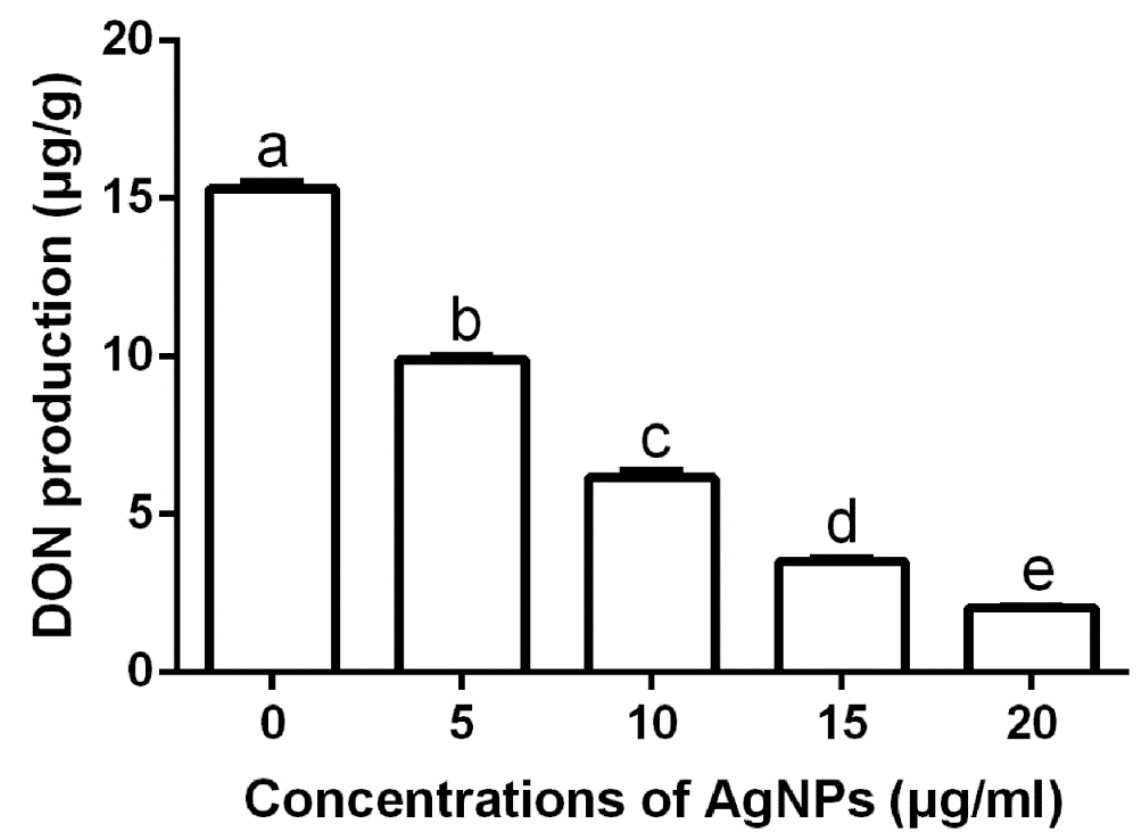

Figure 7. Effect of the synthesized AgNPs of different concentrations on deoxynivalenol (DON) production. The production of the DON of F. graminearum strain PH-1 was inhibited by the biosynthesized AgNPs in vitro. Data are a mean value \pm standard error of three replicates, and bars with the same letters are significantly different in LSD test $(p<0.05)$.

\subsection{Characterization of the Biosynthesized AgNPs}

The biosynthesized AgNPs with strong antifungal activity were further characterized based on the analysis of FTIR, XRD, TEM, SEM and EDS in this study. The functional groups of the synthesized AgNPs were identified based on the FTIR analysis. Indeed, six peaks at 3419, 2923, 1635, 1395, 1075, and $523 \mathrm{~cm}^{-1}$ were observed in the FTIR spectra of biosynthesized AgNPs, as shown in Figure 8A. Based on previous publications, these peaks were able to be attributed to the corresponding functional groups. For example, the peak at $3419 \mathrm{~cm}^{-1}$ was assigned to the NH stretching of Amide A [41]. The peak at $2923 \mathrm{Cm}^{-1}$ indicated the $\mathrm{CH}$ stretch of alkanes [42]. The peak at $1635 \mathrm{Cm}^{-1}$ could be denoted by the carbonyl stretching vibration [43]. The peak at $1395 \mathrm{~cm}^{-1}$ indicated the $\mathrm{O}-\mathrm{C}-\mathrm{H}, \mathrm{C}-\mathrm{C}-\mathrm{H}$ and $\mathrm{C}-\mathrm{O}-\mathrm{H}$ bending vibrational modes of the carbohydrates [44]. The peaks at 1075 and $523 \mathrm{~cm}^{-1}$ could be assigned to the $(\mathrm{C}-\mathrm{O})$ of an alkoxy group [45] and $\mathrm{CH}_{2}$ groups [46], respectively. 
A

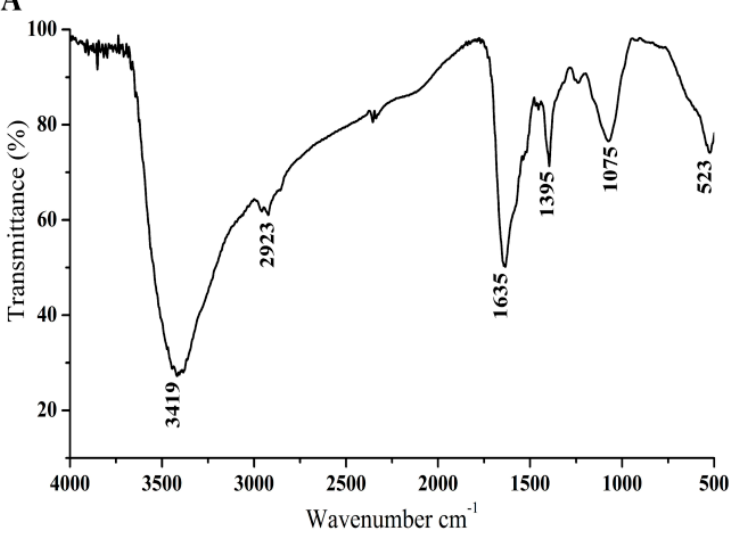

B

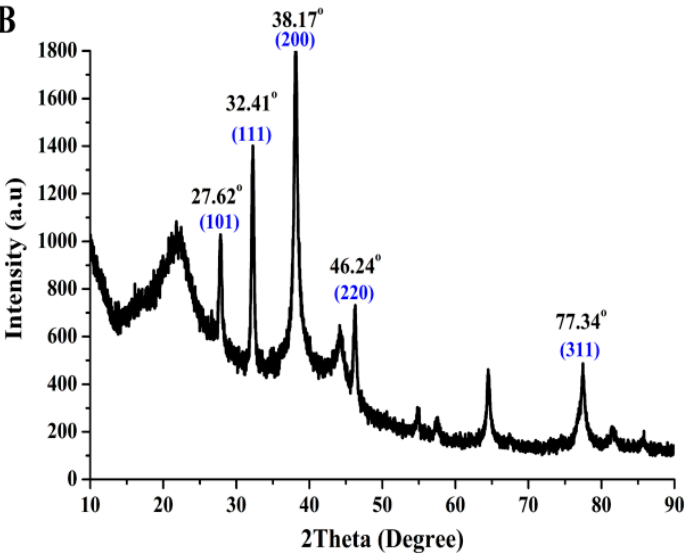

Figure 8. Characterization of the biosynthesized AgNPs after four days of incubation. (A) Fouriertransform infrared spectrum of biosynthesized AgNPs. (B) X-ray diffraction patterns of the biosynthesized AgNPs.

In agreement with the finding of other studies [22,47], the results of this study suggest that the crystallization of bio-organic compounds may occur on the surface of biosynthesized AgNPs. Indeed, the crystalline nature of the biosynthesized AgNPs was determined based on the result of XRD analysis, which indicated that there were five emission peaks of $2 \theta=27.62^{\circ}, 32.41^{\circ}, 38.17^{\circ}, 46.24^{\circ}$ and $77.34^{\circ}$, corresponding to the silver crystal planes (101), (111), (200), (220), and (311), respectively (Figure 8B).

The structure and morphological shape of the biosynthesized AgNPs were determined by using both TEM and SEM observation. The results of this study indicated that the biosynthesized AgNPs were spherical and had a size of 19.8-44.9 nm (Figure 9). In general, the results are consistent with the data from a lot of previous reports $[20,22,48]$. Furthermore, the results of EDS showed that the peak elements of silver and sulfur were $99.40 \%$ and $0.60 \%$, respectively, in the biosynthesized AgNPs (Figure 10). In addition, in agreement with the results obtained in previous studies $[17,49]$, the peak of the silver ions was formed at $3 \mathrm{KeV}$, a fact that could be useful in reducing $\mathrm{Ag}^{+}$to $\mathrm{Ag}^{0}$.
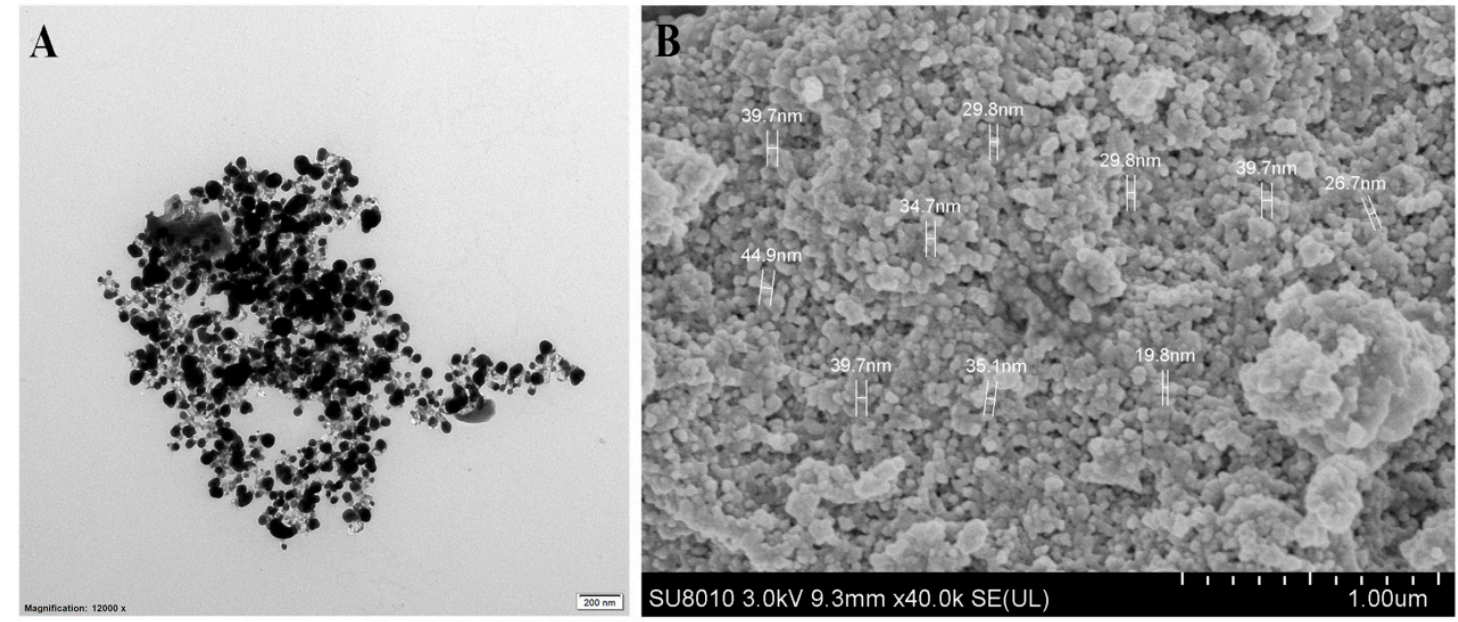

Figure 9. Size and morphology of silver nanoparticles (AgNPs) that were synthesized by reducing $3 \mathrm{mM} \mathrm{AgNO}_{3}$ by using culture filtrates of the endophytic bacterium P. poae strain CO. (A) transmission electron microscopy and (B) scanning electron microscopy. 


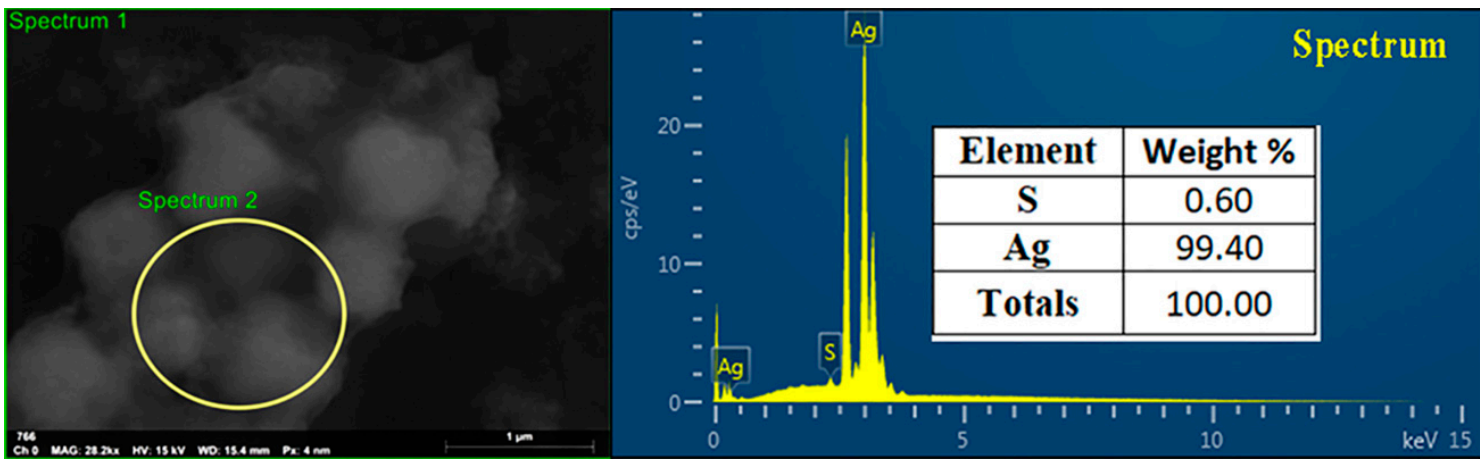

Figure 10. Energy dispersive spectrum showing the predominance of Ag and S elements in the AgNPs.

\section{Conclusions}

To overcome the disadvantages caused by physical and chemical methods, biological methods are a safe alternative for the synthesis of AgNPs. In this study, the biosynthesis of AgNPs was first carried out by an endophytic bacterium that was isolated from garlic. The formation of AgNPs was confirmed by visible UV spectroscopy. In addition, the biosynthesized AgNPs showed strong antifungal activity against the Fusarium head blight pathogen F. graminearum strain $\mathrm{PH}-1$, which may be at least partially attributed to their inhibition on spore germination, germ tube growth, mycotoxin production, and the damage of cell membrane. Furthermore, the biosynthesized AgNPs with strong antifungal activity were characterized by FTIR, XRD, SEM, TEM, and EDS analyses. In general, the result of this study indicate that the synthesized AgNPs have a great potential to protect wheat plants from fungal infection.

Author Contributions: Conceptualization, E.I., M.Z., and Y.Z.; Methodology, E.I., and Y.Z.; Software, M.Z., and A.F.; data Investigation, E.I.; Supervision, B.L., W.W., Y.W., G.S.; Visualization, Y.C., W.Q.; writing一original draft, E.I., Y.Z., and B.L.; Writing-review \& editing, all the authors contribute to this part. All authors have read and agreed to the published version of the manuscript.

Funding: This research was funded by the National Key Research and Development Program of China (2017YFD0201104, 2018YFD0300900), National Natural Science Foundation of China (31872017, 31571971, 31371904, 31801787, 31901925), Zhejiang Provincial Natural Science Foundation of China (LZ19C140002), Zhejiang Provincial Project (2017C02002; 2019C02006; 2020C02006), Shanghai Agriculture Applied Technology Development Program (2019-02-08-00-08-F01150), the Fundamental Research Funds for the Central Universities, Dabeinong Funds for Discipline Development and Talent Training in Zhejiang University, and Key Subject Construction Program of Zhejiang for Modern Agricultural Biotechnology and Crop Disease Control.

Conflicts of Interest: The authors declare no conflict of interest.

\section{References}

1. Dubin, H.J.; Gilchrist, L.; Reeves, J.; McNab, A. Fusarium Head Scab: Global Status and Future Prospects; E-Publishing, Inc.: El Batan, Mexico, 1996; pp. 13-17.

2. Goswami, R.S.; Kistler, H.C. Heading for disaster: Fusarium graminearum on cereal crops. Mol. Plant. Pathol. 2004, 5, 515-525. [CrossRef]

3. Yu, D.; Zhang, S.; Li, X.; Xu, J.-R.; Schultzhaus, Z.; Jin, Q.A. Gin4-Like Protein Kinase GIL1 Involvement in Hyphal Growth, Asexual Development, and Pathogenesis in Fusarium graminearum. Int. J. Mol. Sci. 2017, 18, 424. [CrossRef] [PubMed]

4. Chen, Y.; Kistler, H.C.; Ma, Z. Fusarium graminearum Trichothecene Mycotoxins: Biosynthesis, Regulation, and Management. Annu. Rev. Phytopathol. 2019, 57, 15-39. [CrossRef] [PubMed]

5. Hongxiang, M.; Yao, J.; Zhou, M.; Zhang, X.; Ren, L.; Yu, G. Molecular breeding for wheat fusarium head blight resistance in Cihina. Cereal Res. Commun. 2008, 36, 203-212. [CrossRef]

6. Wu, D.; Wan, J.; Lu, J.; Wang, X.; Zhong, S.; Schwarz, P.; Chen, B.; Rao, J. Chitosan coatings on lecithin stabilized emulsions inhibit mycotoxin production by Fusarium pathogens. Food Control. 2018, 92, 276-285. [CrossRef] 
7. Wu, D.; Lu, J.; Zhong, S.; Schwarz, P.; Chen, B.; Rao, J. Effect of chitosan coatings on physical stability, antifungal and mycotoxin inhibitory activities of lecithin stabilized cinnamon oil-in-water emulsions. Lebensm-Wiss Technol. 2019, 106, 98-104. [CrossRef]

8. Lakshmeesha, T.R.; Kalagatur, N.K.; Mudili, V.; Mohan, C.D.; Rangappa, S.; Prasad, B.D.; Hashem, A.; Alqarawi, A.A.; Malik, J.A.; Abd_Allah, E.F.; et al. Biofabrication of Zinc Oxide Nanoparticles With Syzygium aromaticum Flower Buds Extract and Finding Its Novel Application in Controlling the Growth and Mycotoxins of Fusarium graminearum. Front. Microbiol. 2019, 10, 1244. [CrossRef]

9. Palazzini, J.M.; Dunlap, C.A.; Bowman, M.J.; Chulze, S.N. Bacillus velezensis RC 218 as a biocontrol agent to reduce Fusarium head blight and deoxynivalenol accumulation: Genome sequencing and secondary metabolite cluster profiles. Microbiol. Res. 2016, 192, 30-36. [CrossRef]

10. Chen, L.; Heng, J.; Qin, S.; Bian, K.A. comprehensive understanding of the biocontrol potential of Bacillus velezensis LM2303 against Fusarium head blight. PloS ONE 2018, 13, e0198560. [CrossRef]

11. Pariona, N.; Mtz-Enriquez, A.I.; Sánchez-Rangel, D.; Carrión, G.; Paraguay-Delgado, F.; Rosas-Saito, G. Green-synthesized copper nanoparticles as a potential antifungal against plant pathogens. RSC Adv. 2019, 9, 18835-18843. [CrossRef]

12. Maluin, F.N.; Hussein, M.Z.; Yusof, N.A.; Fakurazi, S.; Idris, A.S.; Zainol Hilmi, N.H. Preparation of Chitosan-Hexaconazole Nanoparticles as Fungicide Nanodelivery System for Combating Ganoderma Disease in Oil Palm. Molecules 2019, 24, 2498. [CrossRef] [PubMed]

13. Abdallah, Y.; Ogunyemi, S.O.; Abdelazez, A.; Zhang, M.; Hong, X.; Ibrahim, E. The Green Synthesis of $\mathrm{MgO}$ Nano-Flowers Using Rosmarinus officinalis L. (Rosemary) and the Antibacterial Activities against Xanthomonas oryzae pv. oryzae. Biomed. Res. Int. 2019, 2019, 5620989. [CrossRef] [PubMed]

14. Malandrakis, A.A.; Kavroulakis, N.; Chrysikopoulos, C.V. Use of copper, silver and zinc nanoparticles against foliar and soil-borne plant pathogens. Sci. Total Environ. 2019, 670, 292-299. [CrossRef] [PubMed]

15. Khalil, N.M.; El-Ghany, M.N.A.; Rodríguez-Couto, S. Antifungal and anti-mycotoxin efficacy of biogenic silver nanoparticles produced by Fusarium chlamydosporum and Penicillium chrysogenum at non-cytotoxic doses. Chemosphere 2019, 218, 477-486. [CrossRef] [PubMed]

16. Fouad, H.; Hongiie, L.; Hosni, D.; Wei, J.; Abbas, G.; Ga'al, H. Controlling Aedes albopictus and Culex pipiens pallens using silver nanoparticles synthesized from aqueous extract of Cassia fistula fruit pulp and its mode of action. rtif. Cells Nanomed. Biotechnol. 2018, 46, 558-567. [CrossRef]

17. Masum, M.M.I.; Siddiqa, M.M.; Ali, K.A.; Zhang, Y.; Abdallah, Y.; Ibrahim, E. Biogenic Synthesis of Silver Nanoparticles Using Phyllanthus emblica Fruit Extract and Its Inhibitory Action Against the Pathogen Acidovorax oryzae Strain RS-2 of Rice Bacterial Brown Stripe. Front Microbiol. 2019, 10, 820. [CrossRef]

18. Ogunyemi, S.O.; Abdallah, Y.; Zhang, M.; Fouad, H.; Hong, X.; Ibrahim, E. Green synthesis of zinc oxide nanoparticles using different plant extracts and their antibacterial activity against Xanthomonas oryzae pv. oryzae. Artif. Cells Nanomed. Biotechnol. 2019, 47,341-352. [CrossRef]

19. Hossain, A.; Hong, X.; Ibrahim, E.; Li, B.; Sun, G.; Meng, Y. Green Synthesis of Silver Nanoparticles with Culture Supernatant of a Bacterium Pseudomonas rhodesiae and Their Antibacterial Activity against Soft Rot Pathogen Dickeya dadantii. Molecules. Molecules 2019, 24, 2303. [CrossRef]

20. Hu, W.; Gao, Q.; Hamada, M.S.; Dawood, D.H.; Zheng, J.; Chen, Y. Potential of Pseudomonas chlororaphis subsp. aurantiaca strain Pcho10 as a biocontrol agent against Fusarium graminearum. Phytopathol. 2014, 104, 1289-1297.

21. Fouad, H.; Hongjie, L.; Yanmei, D.; Baoting, Y.; El-Shakh, A.; Abbas, G. Synthesis and characterization of silver nanoparticles using Bacillus amyloliquefaciens and Bacillus subtilis to control filarial vector Culex pipiens pallens and its antimicrobial activity. Artif. Cells Nanomed. Biotechnol. 2017, 45, 1369-1378. [CrossRef]

22. Spence, C.; Alff, E.; Johnson, C.; Ramos, C.; Donofrio, N.; Sundaresan, V. Natural rice rhizospheric microbes suppress rice blast infections. BMC Plant Biol. 2014, 14, 130. [CrossRef] [PubMed]

23. Chen, J.; Peng, H.; Wang, X.; Shao, F.; Yuan, Z.; Han, H. Graphene oxide exhibits broad-spectrum antimicrobial activity against bacterial phytopathogens and fungal conidia by intertwining and membrane perturbation. Nanoscale 2014, 6, 1879-1889. [CrossRef] [PubMed]

24. Wu, D.; Lu, J.; Zhong, S.; Schwarz, P.; Chen, B.; Rao, J. Influence of nonionic and ionic surfactants on the antifungal and mycotoxin inhibitory efficacy of cinnamon oil nanoemulsions. Food Funct. 2019, 10, $2817-2827$. [CrossRef] [PubMed] 
25. Li, J.; Duan, Y.; Bian, C.; Pan, X.; Yao, C.; Wang, J. Effects of validamycin in controlling Fusarium head blight caused by Fusarium graminearum: Inhibition of DON biosynthesis and induction of host resistance. Pestic. Biochem. Physiol. 2019, 153, 152-160. [CrossRef] [PubMed]

26. Gao, T.; Zhou, H.; Zhou, W.; Hu, L.; Chen, J.; Shi, Z. The Fungicidal Activity of Thymol against Fusarium graminearum via Inducing Lipid Peroxidation and Disrupting Ergosterol Biosynthesis. Molecules 2016, 21, 770. [CrossRef] [PubMed]

27. Sastry, M.; Mayya, K.; Bandyopadhyay, K. pH Dependent changes in the optical properties of carboxylic acid derivatized silver colloidal particles. Colloids Surface A 1997, 127, 221-228. [CrossRef]

28. Kasithevar, M.; Saravanan, M.; Prakash, P.; Kumar, H.; Ovais, M.; Barabadi, H. Green synthesis of silver nanoparticles using Alysicarpus monilifer leaf extract and its antibacterial activity against MRSA and CoNS isolates in HIV patients. J. Interdiscip. Nanomed. 2017, 2, 131-141. [CrossRef]

29. Roy, A.; Bulut, O.; Some, S.; Mandal, A.K.; Yilmaz, M.D. Green synthesis of silver nanoparticles: Biomolecule-nanoparticle organizations targeting antimicrobial activity. RSC Adv. 2019, 9, 2673-2702. [CrossRef]

30. Mohanpuria, P.; Rana, N.K.; Yadav, S.K. Biosynthesis of nanoparticles: Technological concepts and future applications. J. Nanopart. Res. 2008, 10, 507-517. [CrossRef]

31. Kaur, P.; Thakur, R.; Duhan, J.S.; Chaudhury, A. Management of wilt disease of chickpea in vivo by silver nanoparticles biosynthesized by rhizospheric microflora of chickpea (Cicer arietinum). J. Chem. Technol. Biot. 2018, 93, 3233-3243. [CrossRef]

32. Bernardo-Mazariegos, E.; Valdez-Salas, B.; González-Mendoza, D.; Abdelmoteleb, A.; Camacho, O.T.; Duran, C.C. Silver nanoparticles from Justicia spicigera and their antimicrobial potentialities in the biocontrol of foodborne bacteria and phytopathogenic fungi. Rev. Argent. Microbiol. 2019, 51, 103-109. [CrossRef] [PubMed]

33. Bhagat, M.; Anand, R.; Datt, R.; Gupta, V.; Arya, S. Green Synthesis of Silver Nanoparticles Using Aqueous Extract of Rosa brunonii Lindl and Their Morphological, Biological and Photocatalytic Characterizations. J. Inorg. Organomet. P. 2019, 29, 1039-1047. [CrossRef]

34. Elgorban, A.M.; El-Samawaty, A.E.-R.M.; Yassin, M.A.; Sayed, S.R.; Adil, S.F.; Elhindi, K.M. Antifungal silver nanoparticles: Synthesis, characterization and biological evaluation. Biotechnol. Biotec. Eq. 2016, 30, 56-62. [CrossRef]

35. Wang, Z.; Xu, C.; Zhao, M.; Zhao, C. One-pot synthesis of narrowly distributed silver nanoparticles using phenolic-hydroxyl modified chitosan and their antimicrobial activity. RSC Advances 2014, 4, 47021-47030. [CrossRef]

36. Yoshimi, A.; Miyazawa, K.; Abe, K. Function and biosynthesis of cell wall $\alpha-1,3$-glucan in fungi. J. Fungi. 2017, 3, 63. [CrossRef] [PubMed]

37. Xia, Z.-K.; Ma, Q.-H.; Li, S.-Y.; Zhang, D.-Q.; Cong, L.; Tian, Y.-L. The antifungal effect of silver nanoparticles on Trichosporon asahii. J. Microbiol. Immunol. 2016, 49, 182-188. [CrossRef]

38. Dizaj, S.M.; Lotfipour, F.; Barzegar-Jalali, M.; Zarrintan, M.H.; Adibkia, K. Antimicrobial activity of the metals and metal oxide nanoparticles. Mater. Sci. Eng. C 2014, 44, 278-284. [CrossRef]

39. Setlow, P. Spore germination. Curr. Opin. Microbiol. 2003, 6, 550-556. [CrossRef]

40. Hanif, A.; Zhang, F.; Li, P.; Li, C.; Xu, Y.; Zubair, M. Fengycin Produced by Bacillus amyloliquefaciens FZB42 Inhibits Fusarium graminearum Growth and Mycotoxins Biosynthesis. Toxins 2019, 11, 295. [CrossRef]

41. Rasaee, I.; Ghannadnia, M.; Baghshahi, S. Biosynthesis of silver nanoparticles using leaf extract of Satureja hortensis treated with $\mathrm{NaCl}$ and its antibacterial properties. Micropor. Mesopor. Mat. 2018, 264, 240-247. [CrossRef]

42. Vanaja, M.; Gnanajobitha, G.; Paulkumar, K.; Rajeshkumar, S.; Malarkodi, C.; Annadurai, G. Phytosynthesis of silver nanoparticles by Cissus quadrangularis: Influence of physicochemical factors. J. Nanostruct. Chem. 2013, 3, 17. [CrossRef]

43. Benelli, G.; Kadaikunnan, S.; Alharbi, N.S.; Govindarajan, M. Biophysical characterization of Acacia caesia-fabricated silver nanoparticles: Effectiveness on mosquito vectors of public health relevance and impact on non-target aquatic biocontrol agents. Environ. Sci. Pollut. Res. Int. 2018, 25, 10228-10242. [CrossRef] [PubMed]

44. Leopold, L.F.; Leopold, N.; Diehl, H.-A.; Socaciu, C. Quantification of carbohydrates in fruit juices using FTIR spectroscopy and multivariate analysis. J. Spectrosc. 2011, 26, 93-104. [CrossRef] 
45. Ghramh, H.A.; Al-Ghamdi, K.M.; Mahyoub, J.A.; Ibrahim, E.H. Chrysanthemum extract and extract prepared silver nanoparticles as biocides to control Aedes aegypti (L.), the vector of dengue fever. J. Asia-Pac. Entomol. 2018, 21, 205-210. [CrossRef]

46. Kiran, G.S.; Sabu, A.; Selvin, J. Synthesis of silver nanoparticles by glycolipid biosurfactant produced from marine Brevibacterium casei MSA19. J. Biotechnol. 2010, 148, 221-225. [CrossRef]

47. Velu, K.; Elumalai, D.; Hemalatha, P.; Janaki, A.; Babu, M.; Hemavathi, M. Evaluation of silver nanoparticles toxicity of Arachis hypogaea peel extracts and its larvicidal activity against malaria and dengue vectors. Environ. Sci. Pollut. Res. Int. 2015, 22, 17769-17779. [CrossRef]

48. Banu, A.N.; Balasubramanian, C. Extracellular synthesis of silver nanoparticles using Bacillus megaterium against malarial and dengue vector (Diptera: Culicidae). Parasitol. Res. 2015, 114, 4069-4079. [CrossRef]

49. Suganya, G.; Karthi, S.; Shivakumar, M.S. Larvicidal potential of silver nanoparticles synthesized from Leucas aspera leaf extracts against dengue vector Aedes aegypti. Parasitol. Res. 2014, 113, 875-880. [CrossRef]

(C) 2020 by the authors. Licensee MDPI, Basel, Switzerland. This article is an open access article distributed under the terms and conditions of the Creative Commons Attribution (CC BY) license (http://creativecommons.org/licenses/by/4.0/). 